\title{
Evaluation of the use of five laboratory-determined ozone absorption cross sections in Brewer and Dobson retrieval algorithms
}

\author{
A. Redondas ${ }^{1}$, R. Evans ${ }^{2}$, R. Stuebi ${ }^{3}$, U. Köhler ${ }^{4}$, and M. Weber ${ }^{5}$ \\ ${ }^{1}$ Izaña Atmospheric Research Center, AEMET, Tenerife, Canary Islands, Spain \\ ${ }^{2}$ NOAA/OAR/ERSL Climate Monitoring Division, 325 Broadway, Boulder, Colorado 80305, USA \\ ${ }^{3}$ Federal Office of Meteorology and Climatology, MeteoSwiss, Payerne, Switzerland \\ ${ }^{4}$ Deutscher Wetterdienst, Hohenpeissenberg, Germany \\ ${ }^{5}$ Institute of Experimental Physics, University of Bremen, Bremen, Germany
}

Correspondence to: A. Redondas (aredondasm@aemet.es)

Received: 30 June 2013 - Published in Atmos. Chem. Phys. Discuss.: 2 September 2013

Revised: 19 December 2013 - Accepted: 20 December 2013 - Published: 12 February 2014

\begin{abstract}
The primary ground-based instruments used to report total column ozone (TOC) are Brewer and Dobson spectrophotometers in separate networks. These instruments make measurements of the UV irradiances, and through a well-defined process, a TOC value is produced. Inherent to the algorithm is the use of a laboratory-determined crosssection data set. We used five ozone cross-section data sets: three data sets that are based on measurements of Bass and Paur; one derived from Daumont, Brion and Malicet (DBM); and a new set determined by Institute of Experimental Physics (IUP), University of Bremen. The three Bass and Paur (1985) sets are as follows: quadratic temperature coefficients from the IGACO (a glossary is provided in Appendix A) web page (IGQ4), the Brewer network operational calibration set (BOp), and the set used by Bernhard et al. (2005) in the reanalysis of the Dobson absorption coefficient values (B05). The ozone absorption coefficients for Brewer and Dobson instruments are then calculated using the normal Brewer operative method, which is essentially the same as that used for Dobson instruments.

Considering the standard TOC algorithm for the Brewer instruments and comparing to the Brewer standard operational calibration data set, using the slit functions for the individual instruments, we find the IUP data set changes the calculated TOC by $-0.5 \%$, the DBM data set changes the calculated TOC by $-3.2 \%$, and the IGQ4 data set at $-45^{\circ} \mathrm{C}$ changes the calculated TOC by $+1.3 \%$.

Considering the standard algorithm for the Dobson instruments, and comparing to results using the official 1992 ozone
\end{abstract}

absorption coefficients values and the single set of slit functions defined for all Dobson instruments, the calculated TOC changes by $+1 \%$, with little variation depending on which data set is used.

We applied the changes to the European Dobson and Brewer reference instruments during the Izaña 2012 Absolute Calibration Campaign. With the application of a common Langley calibration and the IUP cross section, the differences between Brewer and Dobson data sets vanish, whereas using those of Bass and Paur and DBM produces differences of 1.5 and $2 \%$, respectively. A study of the temperature dependence of these cross-section data sets is presented using the Arosa, Switzerland, total ozone record of 2003-2006, obtained from two Brewer-type instruments and one Dobsontype instrument, combined with the stratospheric ozone and temperature profiles from the Payerne soundings in the same period. The seasonal dependence of the differences between the results from the various instruments is greatly reduced with the application of temperature-dependent absorption coefficients, with the greatest reduction obtained using the IUP data set.

\section{Introduction}

The routine measurement of TOC started in the mid-1920s with a prototype of the Dobson instrument (Dobson, 1968b) as a part of studies of atmospheric circulation. A worldwide network developed after the instrument redesign in 1947 and 
the International Geophysical Year in 1957. Until the late 1970s, this was the only optical dispersing instrument for determining TOC. The Brewer ozone spectrometer was developed in Canada during the 1970s, and an automated commercial version became available in the early 1980s (Kerr et al., 1981). As observing organizations began to purchase these instruments and place them in service alongside the Dobson instrument for long-term measurements, the seasonal and systematic bias in the results became evident. The initial difference (Kerr et al., 1985; Köhler, 1986) of $4 \%$ was strongly reduced with the adoption of absorption coefficients based on the work of Bass and Paur (1985) for the Dobson instrument in 1992 (Kerr et al., 1988). As measurements continued, a seasonal and offset difference was still evident (Vanicek, 2006; Vaníček et al., 2012). With the consideration of replacing the manually operated Dobson instruments with automated Brewer ones, some "transfer function" schemes using statistical regression methods were considered (Scarnato et al., 2010). The methods can be quite successful, but they do not fully explain the reasons for the differences.

The difference in the results of measurements made in the same place is not limited to the primary ground-based networks. In 2009, the ozone community established the ACSO committee ("Absorption Cross Sections of Ozone") to review the presently available cross-section databases and to determine the impact of a change of the reference cross section for the different instrument types (ground-based and satellite) used in the individual instrument retrieval algorithms. The cross sections used in this study are accessible at the ACSO initiative web page (http://igaco-o3.fmi.fi/ACSO/). This ACSO committee is a joint commission of the Scientific Advisory Group for Ozone of the Global Atmosphere Watch program, a part of the World Meteorological Organization, and the International Ozone Commission of the International Association of Meteorology and Atmospheric Sciences.

Our study will investigate the differences due to different determination of cross sections as well as the limitations of the retrieval algorithms. There are other instrumental issues that can cause differences between the instruments that this study does not address, but have some bearing on our results:

- Both instrument types have demonstrated levels of internal stray light (Dobson, 1968a; Bais et al., 1996). The effect of the stray light is such that TOC is underestimated at ozone high slant path values ( $\mu X$ is defined as the product of the optical path length through the atmosphere with the calculated ozone). As high $\mu X$ values correspond to low sunlight and high TOC, the effect is seasonal. Individual instruments have different levels of stray light. Brewer instruments are either single or double monochromators, the latter having demonstrably lower levels of internal stray light.

- The retrievals use a calculation for optical path length $(\mu)$ through the absorbing region in the atmosphere.
The calculation used in the Dobson algorithm is different than that for Brewer retrievals. This small difference is dependent on the station and the time of day, and produces a small difference in the calculated ozone that is correlated with $\mu$.

- $\mathrm{SO}_{2}$ is an interfering absorber (Komhyr and Evans, 1980) in the spectral region used by both the Dobson and Brewer instruments. Our study is restricted to the results in unpolluted atmospheres; the real data examples are from clean, high-altitude sites.

- The Dobson instrument uses three wavelength pairs designated as

$$
\begin{aligned}
& \text { - A (A1:305.5/A2:325.0 nm), } \\
& \text { - C (C1:311.5/C2:332.4 nm), } \\
& \text { - D (D1:317.5/D2:339.9 nm). }
\end{aligned}
$$

To minimize the effect of atmospheric aerosols, measurements are made in double-pair combinations (AD and $\mathrm{CD}$ ). The resultant ozone from the $\mathrm{AD}$ and $\mathrm{CD}$ combinations do not agree under many conditions. This difference is well known, and instructions to account for this difference are described in the standard operating procedures (Komhyr and Evans, 2006). This study will concentrate on the results of combination AD.

\section{Materials and methods}

\subsection{Theory of measurements}

The basic measurement principle for both instruments is the same, and is an application of the Beer's Law. The thickness of the ozone layer is determined by comparing the intensity of solar radiation that has passed through the atmosphere at wavelengths in the ultraviolet that are strongly and weakly absorbed by ozone. Dobson instruments utilize a variable attenuator called an "optical wedge" to measure the intensity ratio of two wavelengths, whereas Brewer instruments directly measure the intensity of sunlight at multiple wavelengths. Intensity ratios are then determined from the measurements.

The general ozone calculation in either the Dobson or Brewer retrieval algorithm can be summarized by the following expression:

$X=\frac{N-B}{A \mu}$,

where $N$ is a linear combination of the logarithm of the measured spectral direct irradiances, extraterrestrial $\left(I_{o}\right)$ (see Sect. 3.2.1), and at ground level (I) at selected $n$ wavelengths. $A$ is the ozone absorption coefficient or differential cross section (DXS), $\mu$ is the ozone air mass, and $B$ is the 
Rayleigh coefficient, which are linear combinations of the ozone absorption $(\alpha)$ and Rayleigh molecular scattering $(\beta)$, respectively, at corresponding wavelengths.

$$
\begin{aligned}
& N=\sum_{i=1}^{n} w_{i} \log \left(\frac{I_{i}}{I_{o i}}\right), \\
& A=\sum_{i=1}^{n} w_{i} \alpha_{i}, \\
& B=v \frac{p}{p_{o}} \sum_{i=1}^{n} w_{i} \beta_{i},
\end{aligned}
$$

where $\alpha_{i}$ and $\beta_{i}$ are the convolutions of the instrument slit function $(S)$ with the ozone and Rayleigh cross sections; $w_{i}$ are the weighting coefficients; $p$ and $p_{0}$ are the atmospheric pressure at the station and sea level, respectively; and $v$ the Rayleigh air mass. As Dobson instruments only measure intensity ratios, the weighting coefficients $\left(w_{i}\right)$ are always 1 or -1 for the double pairs of wavelengths $\left(\lambda_{i}\right)$. The coefficients for the Brewer instruments were selected to eliminate the $\mathrm{SO}_{2}$ absorption, and as the coefficients verify $\sum_{1=1}^{n} w_{i} \lambda_{i}=0$, all linear effects with wavelengths, such as the aerosol absorption, are negligible.

The ozone cross-section database used for the Brewer and Dobson network is from Bass and Paur (1985), as recommended by the International Ozone Commission (http: //www.esrl.noaa.gov/gmd/ozwv/dobson/papers/coeffs.html). The Dobson absorption coefficient calculation is described in Komhyr et al. (1993) and the re-evaluation is described by Bernhard et al. (2005). The results of our calculations of absorption coefficients for the Dobson instrument are compared to the results in these publications.. The Brewer calculation follows the operative procedure (Gröbner et al., 1998; Kerr, 2002) used by the Regional Brewer Calibration Centre-Europe (RBCC-E) for the calibration campaigns. As a brief explanation, the individual wavelengths in the Brewer measurement set are detected at the focal plane of the spectrometer through the use of a stainless steel mask consisting of seven slits, and the particular wavelength is determined by analyzing the measurements of a series of discharge lamps. Following this the wavelength setting is optimized to minimize the effect of wavelength shift during the operation of the instrument. This wavelength calibration process determines the central wavelength and full width at half maximum (FWHM) of each slit. For comparison in this work, we use the Brewer operative method, which is essentially the same as the approximation method of Bernhard et al. (2005) (see Eq. 5):

$\alpha_{i}=\frac{\int \sigma(\lambda) S_{i}(\lambda) \mathrm{d} \lambda}{\int S_{i}(\lambda) \mathrm{d} \lambda}$,

where $S$ is the instrument slit function for the corresponding wavelength and $\sigma$ the ozone cross section at a temperature, i.e., $-46.3{ }^{\circ} \mathrm{C}$ for the Dobson network and $-45^{\circ} \mathrm{C}$ for Brewer instruments (Fig. 1).

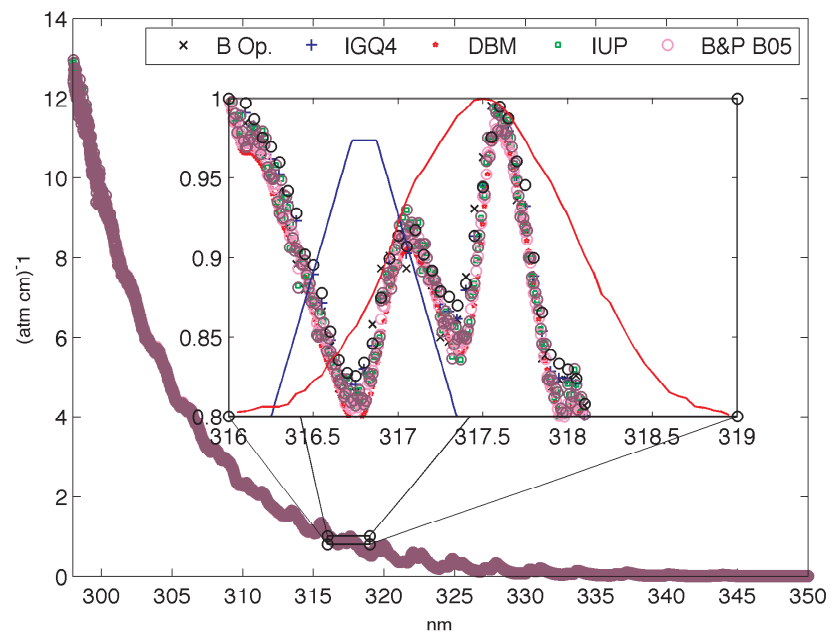

Fig. 1. The cross sections used in this study (Brewer operative Bass and Paur (BOp); Bass and Paur IGACO quadratic fit (IGQ4); Daumont, Brion and Malicet (DBM); Bremen Institute of Atmospheric Physics (IUP); and Bass and Paur of Bernhard (B05) at 228 K) vs. wavelength. Also shown are the representative slit functions of Brewer and Dobson instruments in the spectral region of $317 \mathrm{~nm}$.

In the Dobson network, all instruments are assumed to have the same wavelength registration and slit functions as the World Primary Dobson Spectrometer D083; consequently, each instrument uses the same absorption coefficients in the ozone retrieval. In contrast, the wavelengths and slit functions (and thus the absorption coefficient) for each individual Brewer instrument are determined during the calibration process and are slightly different from nominal values.

In this work the particular Dobson and Brewer instruments are labeled as D or B followed by the fabrication number. The reference Dobson instrument is the denoted by D064 and the RBCC-E Brewer instruments by B157, B183, and B185.

\subsection{Ozone cross sections}

There are three versions of Bass and Paur (1985) cross sections used in this study; these are referred to as BOp (Brewer operational), IGQ4 (IGACO quadratic coefficient), and Bernhard (2005) (B05):

- BOp is the file provided by Environment Canada and used by the RBCC-E and the rest of the Brewer network to derive the individual instrument ozone absorption coefficients. This is equivalent to the published data of Bass and Paur (1985) without any other adjustment (Kerr, 2002). This data set has six temperatures per wavelength registration and agrees with Fig. 2 of Bass and Paur (1985); however, the wavelength range is restricted to the Brewer instrument range (297-332 nm). This file is not available on the IGACO web page but can be downloaded from 


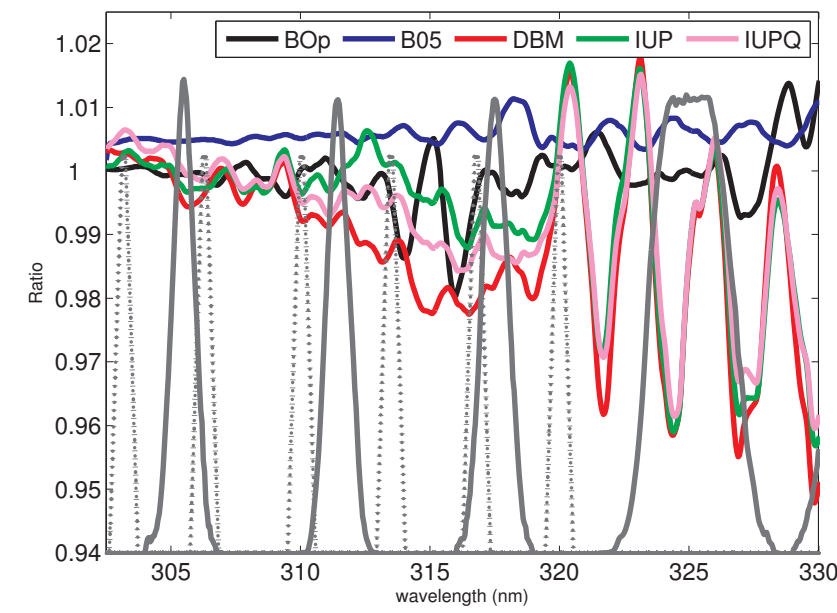

Fig. 2. Ratio of the cross sections of this study to the IGACO Bass \& Paur (IGQ4). The cross sections are interpolated to a common resolution base on that of B\&P $(0.1 \mathrm{~nm})$ and smoothed to the Brewer resolution (triangle slit with FWHM of $0.6 \mathrm{~nm}$ ). The Dobson (continuous) and Brewer (dotted) slit functions are shown in gray. DBM and IUP show the same structures compared with B\&P. There is a small but significant difference between the interpolated value of IUP and the values from the quadratic polynomial (IUPQ).

the RBCC web page and the MPI Mainz spectral database (http://www.atmosphere.mpg.de/enid/2295). However, the MPI Mainz database is in a different format, and some information at important temperatures and wavelengths is missing.

- IGQ4: there are two different sets available at the IGACO web page: one with the individual temperatures and the other with the coefficients of the quadratic fit of the temperature dependence on the file "Bp.par". The six individual temperatures files do not agree with the original Bass and Paur (1985) publication and do not include values at $-45^{\circ} \mathrm{C}$, which is used in Brewer calculations. This data set appears to be calculated at selected temperatures using the quadratic polynomial obtained from the fit of the original data but excluding the $218 \mathrm{~K}$ set (Weber et al., 2013). In this work, we use the data set expressed as quadratic coefficients to be consistent with the technique used in Komhyr et al. (1993). Following the instructions on the IGACO web page, we extracted the values at $-45^{\circ} \mathrm{C}$ from IGACO and compared them to the BOp values also at $-45^{\circ} \mathrm{C}$. The values are similar to the BOp set but are more variable.

- Bernhard (2005): in order to compare our results for the Dobson instrument with Bernhard dynamical results (Bernhard et al., 2005), this special data set was obtained directly from the authors. The data set is that of Bass and Paur (1985) corrected by temperature dependence based on the results of Barnes and
Mauersberger (1987) and extended above $340 \mathrm{~nm}$ with the Molina and Molina (1986) cross section. Further refinement includes convolving the data set with the 1986 US Standard Atmosphere temperature profile, a midlatitude ozone profile and top-of-the-atmosphere solar spectrum.

In addition we use two high-resolution cross sections available at IGACO web page:

- Daumont et al. (1992), Brion et al. (1993), and Malicet et al. (1995) (DBM): this high-resolution set has been measured at five temperatures. We use the quadratic fit, labeled DBMQ, for the temperature dependence studies. For comparison we also use the Liu et al. (2007) quadratic approximation (DBML), which excludes the $273^{\circ} \mathrm{K}$ data from the quadratic temperature fitting.

- The newly determined data set from the University of Bremen (IUP) (Serdyuchenko et al., 2013; Gorshelev et al., 2013) is also available from IGACO and includes 10 temperatures files (IUP) and the quadratic polynomial approximation (IUPQ).

For consistency the wavelengths were referenced to air using the Bernhard tool in the "Libradtran" package (Mayer and Kylling, 2005), and using the $-45^{\circ} \mathrm{C}$ temperature for Brewer and $-46.3^{\circ} \mathrm{C}$ for Dobson calculations; when these temperatures were not available on the cross-section set, a linear interpolation was used. In Fig. 2 the ratio of the various cross section data to IGQ4 at $-45^{\circ} \mathrm{C}$ is shown, and the values of both the interpolated IUP at $-45^{\circ} \mathrm{C}$ and the quadratic approximation IUPQ are also displayed. The units of the cross sections in this work are atm cm ${ }^{-1}$ in logarithmic base 10 scale, as is used in Dobson and Brewer network, using the value for the Loschmidt number $2.687 \times 10^{-19} \mathrm{~cm}^{-3}$.

\subsection{Slit functions}

In the Dobson instrument, the spectrum is moved across two slits. Measurements are performed via the wavelength selector in one of three defined positions. This means there are six slit functions used in the derivation of the absorption coefficients. Originally there were only two slit functions, one estimated as a triangle for the short wavelength, and the other a trapezoid for the long wavelength. There are two measured slit function sets used for the Dobson instrument: the set measured on the Dobson 083 (Komhyr et al., 1993) and the trapezoid parameterization of the Komhyr-measured slits by Bernhard et al. (2005). For the Brewer instrument we also use a parameterization for the slits; the slits are considered a truncated isosceles triangle where the central wavelength and FWHM are determined from the wavelength calibration. Note that in other works, different slit parameterizations for Brewer are used: for example, Van Roozendael et al. (1998) used a Gaussian fit, Serdyuchenko et al. (2013) 
Table 1. Wavelengths and weighting coefficients used in the Dobson and Brewer operative algorithms. The Brewer values are the mean and standard deviation of central wavelength and full width at half maximum (FWHM) of the slits of the "average" Brewer instrument determined during RBCC-E campaigns. The Dobson values correspond to the nominal values published in the Dobson handbook. The values for the World Standard Dobson 83 are available from Komhyr et al. (1993). Note that only the last four wavelengths are used for the Brewer ozone calculation.

\begin{tabular}{lccccccccrr}
\hline $\begin{array}{l}\text { Brewer } \\
\text { slits }\end{array}$ & Wavelength & SD & FWHM & SD & $w_{i}$ & $\begin{array}{r}\text { Dobson } \\
\text { slits }\end{array}$ & Wavelength & FWHM & $\begin{array}{r}w_{i} \\
\text { AD }\end{array}$ & $\begin{array}{r}w_{i} \\
\text { CD }\end{array}$ \\
\hline 0 & 303.001 & & & & 0 & A1 & 305.5 & 0.9 & 1 & 0 \\
2 & 306.301 & 0.014 & 0.548 & 0.016 & 0 & C1 & 311.5 & 0.9 & 0 & 1 \\
3 & 310.051 & 0.014 & 0.539 & 0.015 & 1 & D1 & 317.5 & 0.9 & 1 & 1 \\
4 & 313.501 & 0.015 & 0.555 & 0.012 & -0.5 & A2 & 325.0 & 2.9 & -1 & 0 \\
5 & 316.801 & 0.017 & 0.545 & 0.012 & -2.2 & C2 & 332.4 & 2.9 & 0 & -1 \\
6 & 320.002 & 0.019 & 0.538 & 0.012 & 1.7 & D2 & 339.9 & 2.9 & -1 & -1 \\
\hline
\end{tabular}
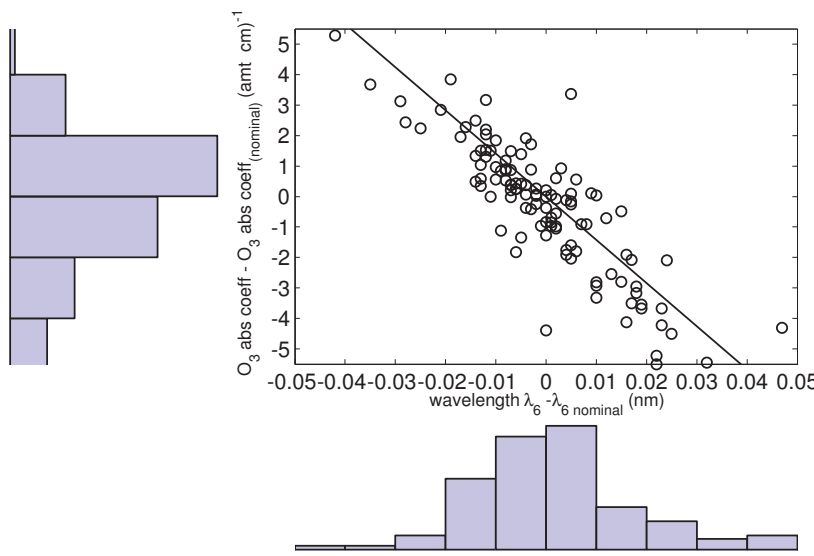

Fig. 3. Difference of the operative ozone absorption coefficient for each individual instrument to the nominal instrument vs. the difference of the wavelength $6(320 \mathrm{~nm})$ to the nominal value. The DXS is proportional to the wavelength difference.

used a rectangular parameterization, and Redondas and Cede (2006) and Fragkos et al. (2013a) used laser measurements.

The RBCC-E has been conducting intercomparisons of Brewer instruments in the European region since 2003. In this work we use a set of 123 wavelength calibrations performed on 33 instruments during these campaigns. This allows us to define an "average" Brewer instrument (Table 1) by defining the average wavelengths of the set as nominal wavelengths; $80 \%$ of the analyzed instruments differ from these wavelengths by less than $0.2 \AA$ compared to the average Brewer instrument (Fig. 3). The application of the DXS methodology to the average Brewer wavelengths characteristics gives a value that is the same as the average of the individual DXS.

The DXS for an individual Brewer instrument will differ slightly from this "average" Brewer instrument. The difference is directly proportional to the difference in center wavelength from the nominal wavelength, as shown in Fig. 3 (Savastiouk, 2010).

\subsection{Temperature dependence}

The ozone absorption coefficient is calculated from the ozone absorption cross section and the vertical profiles of ozone $X(z)$ and temperature $T(z)$ :

$\alpha(\lambda)=\frac{\int \sigma(\lambda, T(z)) X(z) \mathrm{d} z}{\int X(z) \mathrm{d} z}$.

Due to the finite bandwidth of Brewer and Dobson slit functions, the ozone absorption coefficient has to be replaced with an effective ozone absorption (Vanier and Wardle, 1969; Basher, 1982):

$\alpha(\lambda)=\frac{\log \left(\frac{\int E_{o}(\lambda) S\left(\lambda, \lambda_{i}\right) 10^{-\alpha(\lambda) X \mu-\beta(\lambda) \frac{P}{P_{o}} v} d \lambda}{\int E_{o}(\lambda) S\left(\lambda, \lambda_{i}\right) 10^{-\beta(\lambda) \frac{P}{P_{o}} v} d \lambda}\right)}{X \mu}$,

where $E_{o}$ is the extraterrestrial spectral irradiance.

For the complete calculation, the ozone and temperature profiles are needed and applied in a radiative transfer model considering the complete transmission through the atmosphere (Komhyr et al., 1993). In this work we use the simplest approach of Komhyr et al. (1993) - also used by Van Roozendael et al. (1998), Scarnato et al. (2009), and Fragkos et al. (2013b) - which is based on two simple assumptions:

1. The temperature dependence of the cross section is approximated by a quadratic polynomial:

$\sigma(T)=c_{o}+c_{1} T+c_{2} T^{2}$.

2. The effect of the temperature and ozone profile integration can be simplified by the introduction of the effective temperature, which is the ozone-weighted temperature average (Thomas and Holland, 1977):

$$
T_{\text {eff }}=\frac{\int_{z_{o}}^{\infty} T(z) X(z) \mathrm{d} z}{\int_{z_{o}}^{\infty} X(z) \mathrm{d} z} .
$$


Table 2. Summary of Dobson ozone absorption coefficient in atm $\mathrm{cm}^{-1}$, determined from the five ozone cross sections (see text for details) using measured slit functions and parameterized slit functions. Values from Komhyr and Bernard are also displayed for comparison. The calculations using B\&P cross sections by Bernhard et al. (2005) (B05) are also calculated for the parameterized slit functions.

\begin{tabular}{|c|c|c|c|c|c|c|c|c|c|c|c|c|c|c|}
\hline & \multicolumn{4}{|c|}{ Measured slit } & \multicolumn{5}{|c|}{ Parameterized slit } & \multicolumn{5}{|c|}{ Prior determinations } \\
\hline & $\mathrm{BOp}$ & IGQ4 & DBM & IUP & $\mathrm{BOp}$ & IGQ4 & DBM & IUP & $\begin{array}{l}\text { B\&P } \\
\text { B05 }\end{array}$ & $\begin{array}{l}\text { Komhyr } \\
\text { approx. }\end{array}$ & $\begin{array}{c}\text { Komhyr } \\
1993\end{array}$ & $\begin{array}{c}\text { Komhyr } \\
\text { Op. }\end{array}$ & $\begin{array}{c}\text { B05 } \\
\text { approx. }\end{array}$ & B05 \\
\hline $\mathrm{A} 1$ & 1.901 & 1.900 & 1.895 & 1.897 & 1.903 & 1.902 & 1.897 & 1.899 & 1.915 & 1.917 & 1.915 & & 1.915 & 1.914 \\
\hline A2 & 0.109 & 0.109 & 0.107 & 0.107 & 0.116 & 0.116 & 0.114 & 0.114 & 0.117 & 0.115 & 0.109 & & 0.115 & 0.110 \\
\hline A pair & 1.792 & 1.791 & 1.788 & 1.790 & 1.788 & 1.787 & 1.783 & 1.785 & 1.798 & 1.802 & 1.806 & 1.806 & 1.800 & 1.805 \\
\hline $\mathrm{C} 1$ & 0.862 & 0.862 & 0.856 & 0.862 & 0.861 & 0.861 & 0.855 & 0.862 & 0.868 & 0.870 & 0.873 & & 0.868 & 0.871 \\
\hline $\mathrm{C} 2$ & & 0.038 & 0.038 & 0.038 & & 0.039 & 0.039 & 0.039 & 0.040 & 0.039 & 0.040 & & 0.040 & 0.039 \\
\hline $\mathrm{C}$ pair & & 0.824 & 0.818 & 0.825 & & 0.822 & 0.816 & 0.823 & 0.828 & 0.831 & 0.833 & 0.833 & 0.828 & 0.832 \\
\hline D1 & 0.382 & 0.382 & 0.376 & 0.379 & 0.380 & 0.380 & 0.374 & 0.377 & 0.384 & 0.379 & 0.384 & & 0.384 & 0.387 \\
\hline D2 & & 0.010 & 0.010 & 0.010 & & 0.011 & 0.011 & 0.011 & 0.010 & 0.010 & 0.017 & & 0.010 & 0.010 \\
\hline D pair & & 0.373 & 0.366 & 0.369 & & 0.370 & 0.363 & 0.367 & 0.373 & 0.369 & 0.367 & 0.374 & 0.373 & 0.377 \\
\hline $\mathrm{AD}$ & & 1.419 & 1.422 & 1.421 & & 1.417 & 1.420 & 1.419 & 1.425 & 1.433 & 1.439 & 1.432 & 1.427 & 1.428 \\
\hline CD & & 0.451 & 0.452 & 0.455 & & 0.452 & 0.453 & 0.456 & 0.455 & 0.462 & 0.466 & 0.459 & 0.455 & 0.455 \\
\hline
\end{tabular}

Table 3. Change in calculated ozone for the double wavelength pair combinations from the standard absorption coefficients to the ones derived from the various cross-section data sets.

\begin{tabular}{|c|c|c|c|c|c|c|c|c|c|c|c|}
\hline \multirow{2}{*}{$\begin{array}{l}\text { Wavelength } \\
\text { setting }\end{array}$} & \multicolumn{3}{|c|}{ Measured slit } & \multicolumn{4}{|c|}{ Parameterized slit } & \multicolumn{4}{|c|}{ Prior determinations } \\
\hline & $\begin{array}{r}\text { IGQ4 } \\
\text { B\&P }\end{array}$ & DBM & IUP & IGQ4 & DBM & IUP & $\begin{array}{r}\text { B05 } \\
\text { B\&P }\end{array}$ & $\begin{array}{c}\text { Komhyr } \\
\text { approx. }\end{array}$ & Komhyr & $\begin{array}{r}\text { Bernhard } \\
\text { approx. }\end{array}$ & Bernhard \\
\hline $\mathrm{AD}$ & $0.9 \%$ & $0.7 \%$ & $0.8 \%$ & $1.1 \%$ & $0.8 \%$ & $0.9 \%$ & $0.5 \%$ & $-0.1 \%$ & $-0.5 \%$ & $0.3 \%$ & $0.3 \%$ \\
\hline $\mathrm{CD}$ & $1.7 \%$ & $1.5 \%$ & $0.8 \%$ & $1.5 \%$ & $1.3 \%$ & $0.6 \%$ & $1.0 \%$ & $-0.7 \%$ & $-1.5 \%$ & $0.9 \%$ & $0.9 \%$ \\
\hline
\end{tabular}

The effective absorption coefficient is therefore

$\alpha_{i}\left(T_{\mathrm{eff}}\right)=C_{i o}+C_{i 1} * T_{\mathrm{eff}}+C_{i 2} * T_{\mathrm{eff}}^{2}$,

where the coefficients $C$ are

$C_{i j}=\frac{\int c_{j}(\lambda) S_{i}\left(\lambda, \lambda^{\prime}\right) \mathrm{d} \lambda}{\int S_{i}\left(\lambda, \lambda^{\prime}\right) \mathrm{d} \lambda}$

and finally, the absorption coefficient is

$$
\begin{aligned}
\alpha(T) & =\sum_{i=1}^{n} w_{i} \sum_{j=0}^{2} C_{i j} * T^{j} \\
& =\sum_{i=1}^{n} w_{i} C_{i o}+T \sum_{i=1}^{n} w_{i} C_{i 1}+T^{2} \sum_{i=1}^{n} w_{i} C_{i 2}
\end{aligned}
$$

The quadratic approximation has the same accuracy (1\%) as the cross section (Orphal, 2003; Serdyuchenko et al., 2013) but the choice of the temperatures at which the fit is performed can give different results (Scarnato et al., 2009; Fragkos et al., 2013b). To avoid this issue, and considering that the operative temperature $228 \mathrm{~K}$ is available for most of the cross sections of this study, a linear extrapolation is used for the operational retrieval. The temperature dependence of the cross section is generally expressed as the gradient of the cross section, with a quadratic dependence of temperature, and for a particular measurement with $n$ slits and weights, $w_{i}$ is equal to

$\frac{\Delta A}{\Delta T}=\sum_{i=1}^{n} w_{i}\left[C_{i 1}+2 * C_{i 2} * T\right]$.

This is expressed as percentage change per Kelvin, where $A_{\mathrm{O}}$ is the operative (fixed temperature) cross section.

$100 \frac{\Delta A}{A_{\mathrm{o}} \Delta T}$

The ratio of temperature corrected and uncorrected ozone due to cross-section change is equal to the inverse of the absorption coefficients

$X(T)=X_{0} * \frac{A_{\mathrm{o}}}{A(T)}$,

where $X_{0}$ is the ozone at operative temperature.

\section{Analysis of the results}

\subsection{Operational parameter}

\subsubsection{Dobson calculations}

We used the various cross-section data sets with the measured and parameterized slit functions for D083. The values 


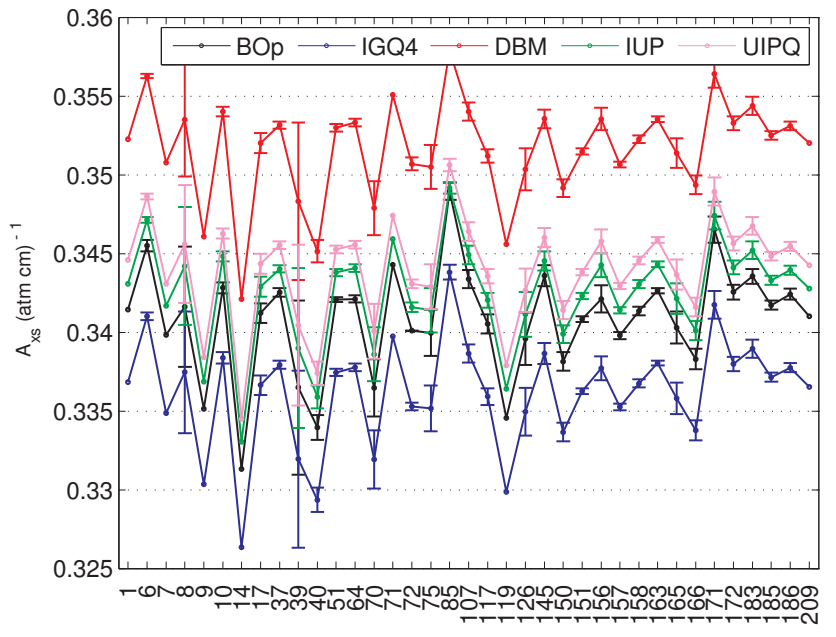

Fig. 4. Brewer ozone absorption coefficient or differential cross section for the Brewer instruments in the RBCC-E set; the values are the mean and the bars indicate the standard deviation for the analyzed cross sections. The Brewer instrument labeled as \#1 is the "nominal" one; the $x$-axis notation is the individual Brewer serial number

obtained are displayed in Table 2. Apart from the (Komhyr et al., 1993) value for the D2 $(339.9 \mathrm{~nm})$ setting, there are only small differences. This was a known problem and addressed in 1993 by using the record of D083 measurements at Mauna Loa Observatory to empirically find a value that was more realistic. The reanalysis in 2005 verified that the empirical value was more correct and that there was an error in the 1993 analysis. Table 3 expresses the percentage difference in calculated ozone that would occur with the use of the various cross-section data sets compared to that calculated using the operational values. As the wavelength range of the BOp does not extend to the $\mathrm{C} 2$ and $\mathrm{D} 2$ slit functions, BOp is omitted.

The comparison with the operational values shows that our derivations are consistent within $1 \%$ for the $\mathrm{AD}$. On the $\mathrm{CD}$ pair the differences are larger, $1.5 \%$, for IGQ4 and DBM, with the values of IUP also $0.5 \%$ higher. The results with parameterized slits are slightly lower than those measured slits (a lower value means that the calculated ozone value will be higher). As the Bernhard B\&P cross sections is available only for $-46.3^{\circ} \mathrm{C}$, it was only used in a derivation for the trapezoid approximation to assess the validity of our numerical method, the four remaining cross sections were calculated for both slits. The validity of the calculation can be checked when we use the same ozone cross section and slit parameterization as Bernhard et al. (2005) on pair wavelengths, and for a double pair we get a maximum difference of $0.15 \%$.

\subsubsection{Brewer calculations}

For the Brewer instruments, we take the results of 123 dispersion tests performed on 33 instruments during the RBCC-E campaigns (Fig. 4) and calculate the absorption coefficients using the operative Brewer procedure described in the previous section. The ratio of each new absorption coefficient to the one determined from the BOp data set was also determined (Fig. 5). The statistics of the ratio results are displayed in Table 4 . The statistics of this set confirm the results for other determinations, such as those using the DBM XS during the Sodankylä Total Column Ozone Intercomparison (SAUNA) (Redondas and Cede, 2006), studies presented at ACSO meeting (Redondas, 2009; Savastiouk, 2010), and a recent study by Fragkos et al. (2013a) (Table 5). However, our results are not in agreement with those of Scarnato et al. (2009), which were also presented at an ACSO meeting. The results of Scarnato et al. (2009) are $4 \%$ lower than our average DBM results, which have a range of $\pm 1.2 \%$. The IUP $\mathrm{XS}$ results are the closest to the operative value (producing $0.5 \%$ higher TOC).

Instrumental differences in the Brewer operative XSdetermined DXS are mirrored in the DXS determined in the other XS data sets (Fig. 4), and is related to the difference of central wavelengths to the nominal value (Fig. 3):

$A_{i, \mathrm{op}}=\widetilde{A_{\mathrm{op}}}+a_{\mathrm{op}} *\left(\lambda_{i}-\tilde{\lambda}\right)$,

where $A_{i, \text { op }}$ are the operative DXS of the instrument $i$ and $\lambda_{i}$ its central wavelength of slit 6 . The tilde values are DXS and wavelength referenced to the nominal instrument and $a_{\mathrm{op}}$ is the proportional constant. The ratios of the different cross sections $A_{\mathrm{xs}}$ to the operative ones $A_{\mathrm{op}}$ for a particular instrument are also related to the difference in wavelengths to the nominal value (Fig. 5):

$A_{i, \mathrm{xs}} / A_{i, \mathrm{op}}=\frac{\widetilde{A_{\mathrm{xs}}}}{\widetilde{A_{\mathrm{op}}}}+a_{\mathrm{xs}}\left(\lambda_{i}-\tilde{\lambda}\right)$.

A summary of these linear relationships can be found in Table 6. The statistics for the relationships described by Eq. (17) can be found in Table 6. This linear relationship allows us to correct past ozone measurements; if we know the operative differential cross section of the instrument $A_{i, \mathrm{op}}$, we can estimate the correction factor for the desired cross section. If we were to apply the nominal Brewer absorption coefficients to all Brewer instruments, the maximum error in calculated TOC would be $0.5 \%$. If this correction factor is applied, the error is reduced to $0.2 \%$. As the wavelength difference between the majority of the test Brewer instruments and the nominal Brewer one is less than $0.02 \mathrm{~nm}$, the error is more likely $0.1 \%$.

\subsubsection{Temperature dependence calculations}

The temperature dependence calculations were performed with IGQ4, DBM and IUP cross sections, as the temperature dependence is not available for the operative cross sections. The results are summarized in Table 7 for the Dobson 083 and a nominal Brewer instrument defined as having the 


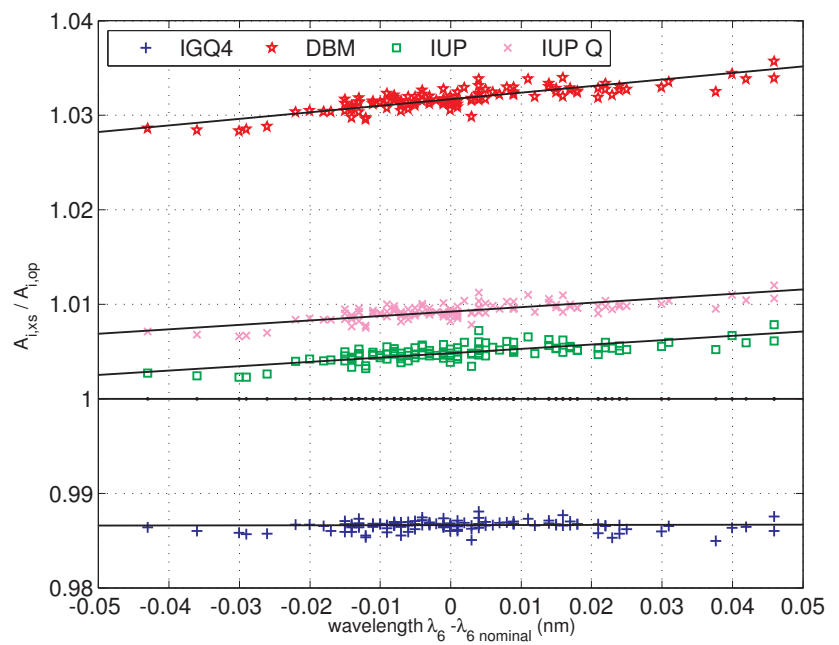

Fig. 5. Ratio of the different cross section $\left(A_{i, \mathrm{xs}}\right)$ to the operative cross-section $\left(A_{i, \mathrm{op}}\right)$ for each Brewer instrument against the difference in wavelength $\left(\lambda_{6}-\lambda_{6}\right.$ (nominal) $)$ to the nominal value for slit 6.

Table 4. Statistics of the ratio of the absorption coefficient $\left(A_{\mathrm{xs}} / A_{\mathrm{op}}\right)$ to the operative cross section (Bop) to that calculated with cross sections of this study: B\&P from the IGACO web page (IGQ4); Daumont, Brion and Malicet (DBM); the University of Bremen (IUP) and the UIP at $-45^{\circ} \mathrm{C}$ from the quadratic fit of IUP set (IUPQ).

\begin{tabular}{lcccc}
\hline$A_{\text {xs }} / A_{\text {op }}$ & IGQ4 & DBM & IUP & IUPQ \\
\hline Mean & 0.987 & 1.032 & 1.005 & 1.009 \\
SD & 0.001 & 0.002 & 0.001 & 0.001 \\
Max & 0.988 & 1.037 & 1.009 & 1.013 \\
Min & 0.985 & 1.025 & 1.000 & 1.004 \\
Range & 0.003 & 0.012 & 0.009 & 0.009 \\
\hline
\end{tabular}

mean central wavelengths and mean FWHM of the RBCCE set. The absorption coefficient temperature dependence of this Brewer instrument and the standard deviation of the 123 calibrations of the RBCC-E set are depicted in Fig. 6 with the Dobson temperature dependence.

These values of the temperature dependence are in general agreement with previous studies using the B\&P and IUP cross sections (Table 8). For the use of DBM, the differences are larger, which might result from the choice of four or five temperatures in the determination of the quadratic approximation for the DBM cross section (Liu et al., 2007; Fragkos et al., 2013a). We cannot explain the difference to the Scarnato et al. (2009) study.

The main conclusions are as follows:

- The calculated IUP temperature dependence for the Brewer instrument is very low, less than $0.01 \%$. For the Dobson instrument, the value is smaller than that published in Komhyr et al. (1993).

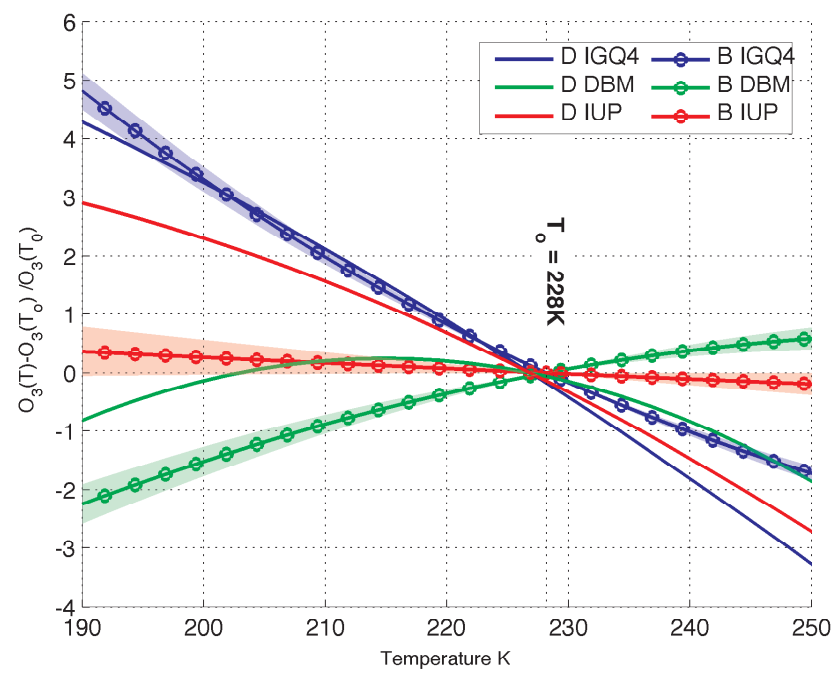

Fig. 6. Dobson AD pair and Brewer calculated total ozone error due to temperature dependence of the various cross-section data sets. The brewer lines correspond to the nominal brewer and the shaded area indicates one standard deviation calculated from the RBCC-E set. In a cooler stratosphere the Dobson (labeled as D) and Brewer instruments (labeled B) underestimate the ozone using IGQ4 (B\&P) and IUP cross sections, whereas they overestimate it if we use DBM. The Brewer temperature dependence of the IUP case is very small.

- The calculated DBM temperature dependence is a small negative value for the Brewer instrument, but is a small positive value for the Dobson instrument.

- The calculated B\&P temperature dependence for the Brewer instrument is lower than that for the Dobson instrument.

The effect on the ozone observations of Dobson and Brewer instruments using comparison data is examined in the next section.

\subsection{Application to real measurements}

\subsubsection{Application to the 2012 Langley campaign at Izaña Observatory}

We can evaluate the effect on the Brewer-Dobson comparison by applying the cross sections determined in this study to the synchronized measurements made during the 2012 Langley campaign at Izaña. Both Dobson and Brewer instruments use the Langley plot method (Langley, 1884) applied to the measured ratios to verify the extraterrestrial constant used in the algorithms to convert measurements to total ozone (Komhyr et al., 1989). If the ozone and other interfering absorbers are constant over half a day, the plot of the measured ratios vs. the air mass $(\mu)$ (see Eq. 1) is a straight line and thus it is possible to extrapolate to air mass zero in order to determine the extraterrestrial value. 
Table 5. Ratio of the differential ozone absorption coefficient to the operative ones compared with results from other studies.

\begin{tabular}{cccccccc}
\hline Brewer & Redondas 2006 & Redondas 2009 & Savastiouk 2010 & \multicolumn{2}{c}{ Scarnato 2009 } & \multicolumn{2}{c}{ Redondas 2013 } \\
s185 & set average \\
\hline DBM & 0.970 & 0.969 & 0.970 & 0.939 & 0.917 & 0.933 & 0.969 \\
\hline
\end{tabular}

Table 6. Statistics of the linear relation of the differences based on Eqs. (16) and (17). The first column gives the differential crosssection $A_{\mathrm{xs}}$ of the different cross section calculated for the nominal Brewer $(\mathrm{atm} \mathrm{cm})^{-1}$, the second column shows the ratio of the differential cross section to the operative value for the nominal instrument, and "a" is the slope of Eq. (17) in atm $\mathrm{cm} \mathrm{nm}^{-1}$. The last column is the R-square coefficient of the linear fit (IGQ4 is flat).

\begin{tabular}{lrrrr}
\hline & $\tilde{A}_{\text {xs }}$ & $\tilde{A}_{\text {xs }} / \tilde{A}_{\text {op }}$ & a & R square \\
\hline BOp & 0.3412 & 1 & - & - \\
IGQ4 & 0.3367 & 0.9865 & 0.004 & - \\
DBM & 0.3521 & 1.0317 & 0.070 & 0.7879 \\
IUP & 0.3430 & 1.0048 & 0.047 & 0.6754 \\
IUPQ & 0.3445 & 1.0092 & 0.048 & 0.6816
\end{tabular}

This campaign was conducted from 20 September to 12 October 2012 at the Izaña Observatory (IZO) under very clear sky conditions. We use 12 "Langley" days, with clear and stable atmospheric conditions, as verified by ultraviolet aerosol optical depth less than 0.05 , measured at $340 \mathrm{~nm}$ by a CIMEL sun photometer. The comparison of Brewer and Dobson instruments during this campaign was in agreement with previous comparisons (Köhler et al., 2012), with an underestimation of $1.5 \%$ of the Dobson instrument with respect to the Brewer one (Fig. 7). It is important to note that the reference for this calculation is the mean of Brewer and Dobson instruments taken separately.

The comparison of the instruments does not show dependence on $\mu \mathrm{X}$, which suggests that the difference between instruments is due to the cross section. The effective temperature showed a small variation as it was very close to the operative value, so its effect is on the measurements is small. The effect on the TOC calculated by Dobson and Brewer instruments based on change of ozone cross-section $\alpha$ to $\alpha^{\prime}$ is simply the ratio between the old and new absorption coefficients (Eq. 15). The factors applied to the synchronized observations of Dobson and Brewer are shown in Table 9. The application of these factors is shown in Fig. 8 and summarized in Table 10. The use of the IGQ4 cross sections does not change the Brewer-Dobson comparison, but it does slightly increase the Dobson CD-AD double pair difference. The DBM increases the difference between the instruments from $1.5 \%$ for the operative algorithm to 2 and $3 \%$ for the case of the $\mathrm{CD}$ and $\mathrm{AD}$ pair, respectively. Finally the IUP significantly reduces the differences between Brewer and Dob-

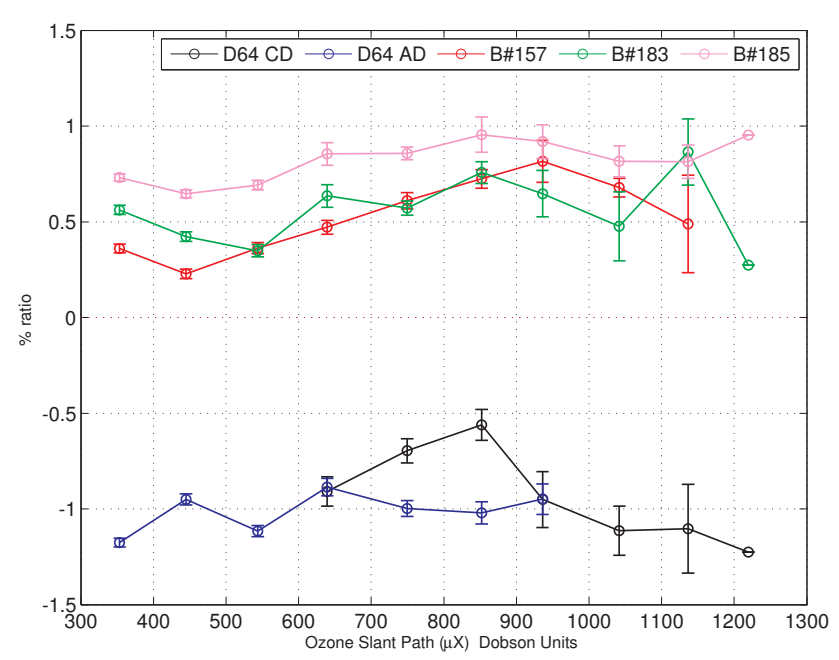

Fig. 7. Brewer-Dobson percentage differences vs. the mean of European reference Brewer (labeled B) and Dobson instruments (labeled D) taken separately versus ozone slant path $(\mu \mathrm{X})$ during the 2012 Langley plot calibration campaign at Izaña Observatory (IZO). With the exception of the Dobson CD pair at high $\mu \mathrm{X}$, there is no evident $\mu \mathrm{X}$ dependence.

son instruments and maintains the differences between $\mathrm{CD}$ and $\mathrm{AD}$ pairs of the operative set.

\subsubsection{Application to the Arosa Brewer vs. Dobson series}

To investigate the various temperature-dependent absorption coefficients with real data, we use Dobson and Brewer observational data from Arosa, Switzerland. This data set consists of $3 \mathrm{yr}$ of TOC observations with the Dobson D101, Brewer B040 (single monochromator) and Brewer B156 (double monochromator) instruments. For the stratospheric temperature at the time of the observations, the ozone-weighted temperature, or effective temperature $T_{\text {eff }}$, was obtained from the Payerne, Switzerland, ozonesonde soundings for the same period (Fig. 9). A quasi-simultaneous set of the observations taken within a 10 min time span was selected and the temperature information taken three times a week interpolated to the time of the Brewer/Dobson measurements. We tested several methods of interpolation, using linear, nearest day values or considering only the days with soundings, but did not find any significant effect on the results. TOC values for the Dobson and Brewer are corrected according to this interpolated temperature measurements using Eq. (15), and we use the quadratic coefficients of $T$ for a "generic Brewer" instrument 
Table 7. Quadratic coefficient of the ozone absorption coefficient $\left(C_{2} \ldots C_{0}\right)$, the absorption coefficient for the operative temperature $A_{\mathrm{o}}$ and the percentage gradient $\Delta$ for the three ozone cross sections calculated for Dobson and Brewer instruments. The operative value is also indicated $\left(A_{\mathrm{op}}\right)$.

\begin{tabular}{|c|c|c|c|c|c|c|c|c|}
\hline & \multicolumn{4}{|c|}{ Brewer $A_{\mathrm{op}}=0.3412$} & \multicolumn{4}{|c|}{ Dobson $A_{\mathrm{op}}=1.4320$} \\
\hline & $\mathrm{B} \& \mathrm{P}$ & DBM & DBML & IUP & $B \& P$ & DBM & DBML & IUP \\
\hline$C_{2}$ & $-2.1989 \times 10^{-6}$ & $1.9801 \times 10^{-6}$ & $7.4771 \times 10^{-6}$ & $-4.9188 \times 10^{-8}$ & $8.2385 \times 10^{-6}$ & $2.4632 \times 10^{-5}$ & $3.0829 \times 10^{-5}$ & $1.0518 \times 10^{-5}$ \\
\hline$C_{1}$ & $1.1747 \times 10^{-4}$ & $4.1821 \times 10^{-5}$ & $3.7060 \times 10^{-4}$ & $2.8781 \times 10^{-5}$ & $2.6428 \times 10^{-3}$ & $2.8713 \times 10^{-3}$ & $3.2420 \times 10^{-3}$ & $2.4502 \times 10^{-3}$ \\
\hline$C_{0}$ & $3.4667 \times 10^{-1}$ & $3.5353 \times 10^{-1}$ & $3.5632 \times 10^{-1}$ & $3.4591 \times 10^{-1}$ & $1.5216 \times 10$ & $1.5025 \times 10$ & $1.5057 \times 10$ & $1.5157 \times 10$ \\
\hline$\alpha$ & $3.3693 \times 10^{-1}$ & $3.5565 \times 10^{-1}$ & $3.5478 \times 10^{-1}$ & $3.4452 \times 10^{-1}$ & $1.4172 \times 10$ & $1.4225 \times 10$ & $1.4217 \times 10$ & $1.4250 \times 10$ \\
\hline$\Delta$ & $9.3601 \times 10^{-2}$ & $-3.8349 \times 10^{-2}$ & $-8.5217 \times 10^{-2}$ & $9.6391 \times 10^{-3}$ & $1.3285 \times 10^{-1}$ & $4.2096 \times 10^{-2}$ & $2.7975 \times 10^{-2}$ & $1.0384 \times 10^{-1}$ \\
\hline
\end{tabular}

Table 8. Summary of temperature dependence of Dobson and Brewer instruments from previous studies in $\% \mathrm{~K}^{-1}$.

\begin{tabular}{|c|c|c|c|c|c|c|c|c|c|c|c|c|c|}
\hline$\% \mathrm{~K}^{-1}$ & \multicolumn{2}{|c|}{ Kerr (1998) } & Kerr (2002) & \multicolumn{2}{|c|}{ Rozendael } & \multicolumn{4}{|c|}{ Scarnato } & Redondas & Fragkos & \multicolumn{2}{|c|}{ This work } \\
\hline Inst. & Dob & \#008 & \#014 & Dob & Brw & Dob & \#040 & $\# 072$ & $\# 156$ & \#185 & \#005 & Dob & Brw \\
\hline B\&P & 0.13 & 0.07 & 0.094 & 0.13 & 0.11 & & 0.081 & 0.099 & 0.088 & 0.09 & 0.097 & 0.133 & 0.094 \\
\hline DBM & & & & & & -0.11 & -0.131 & -0.12 & -0.128 & -0.04 & -0.07 & -0.042 & -0.038 \\
\hline IUP & & & & & & & & & & & 0.019 & 0.104 & 0.009 \\
\hline
\end{tabular}
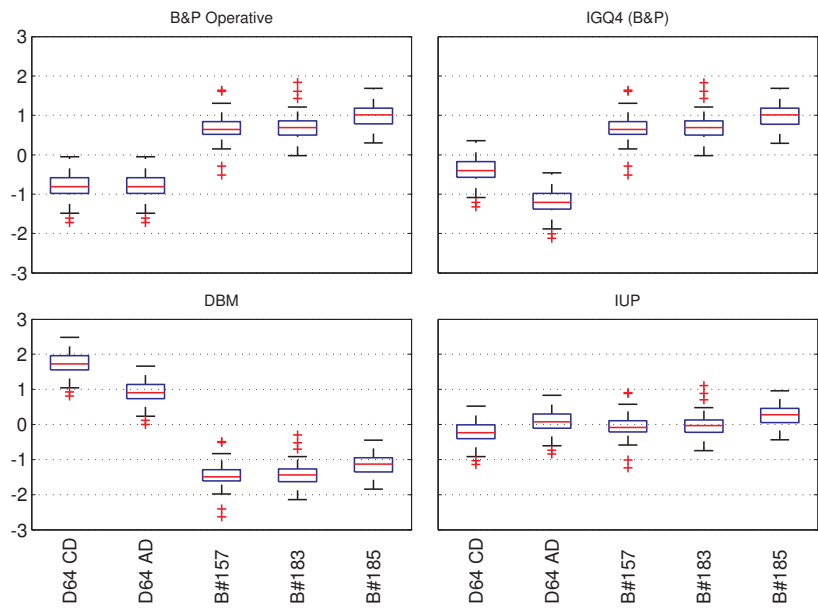

IUP

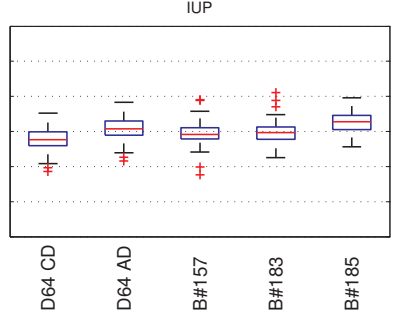

Fig. 8. Box plot of the percentage differences versus the mean of Dobson and Brewer instruments during the 2012 Langley plot calibration campaign at Izaña Observatory for four cross sections: (1) Bass \& Paur Operative (BOp); (2) Bass \& Paur from quadratic coefficients (IGQ4); (3) Daumont, Brion and Malicet (DBM); and (4) the University of Bremen (IUP). The first two boxes in each panel correspond to the Dobson pairs $\mathrm{CD}$ and $\mathrm{AD}$ and the last three to the Brewer triplet used at the RBCC-E.

Table 9. Coefficients used to convert the ozone operational observations of Dobson and Brewer instruments to evaluated cross sections.

\begin{tabular}{lccc}
\hline & IGQ4 & DBM & IUP \\
\hline Brewer & 1.013 & 0.969 & 0.995 \\
Dobson CD & 1.017 & 1.015 & 1.008 \\
Dobson AD & 1.009 & 1.007 & 1.011 \\
\hline
\end{tabular}

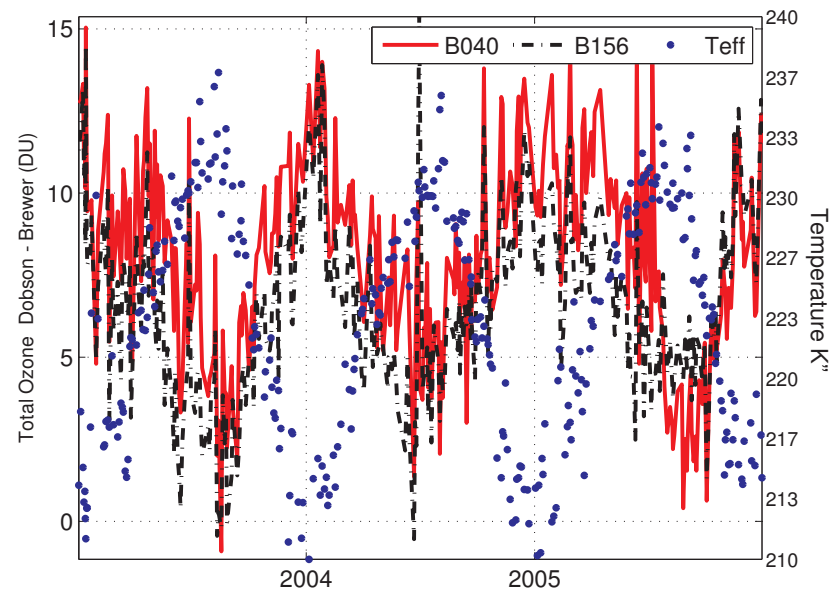

Fig. 9. Daily mean of the Dobson-Brewer total ozone difference for Arosa 2003-2006 and effective temperature. Brewer 040 (B040) is a single-monochromator instrument, while Brewer 156 (B156 )is a double-monochromator instrument.

and the Dobson 083 (Table 7). We also investigated the data set using a DXS determined specifically for the Brewer 040 and 156 instruments and found little difference to the nominal Brewer results. The Brewer 156 instrument is quite similar to the nominal Brewer one, and Brewer 040 instrument is $\sim 0.2 \%$ different. The effect on the seasonal differences is shown in Fig. 10.

The results are similar to the Langley campaign results:

- The DBM-derived absorption coefficients produce a difference of about $2-3 \%$ between the instruments' results. 


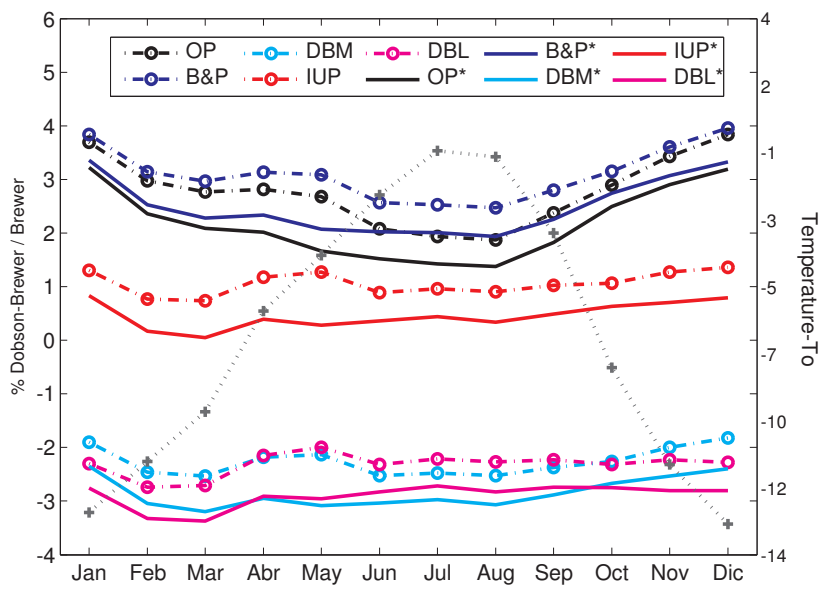

Fig. 10. Monthly means of the Brewer-Dobson differences for the Arosa observations. The different plot lines are derived from ozone calculated using the operational (fixed temperature) algorithms (black lines), and ozone calculated with temperature- dependent algorithms (colored lines). The dotted lines are for singlemonochromator Brewer instruments and the solid lines are for double monochromator Brewer instruments. The effective stratospheric temperature difference between the nominal used in the algorithm and the temperature determined from the Payerne ozonesonde record is also displayed (gray dotted line with gray plus signs).

- The Bass \& Paur-derived absorption coefficients produce a difference of about $2-3 \%$, but in the opposite direction to DBM.

- The IUP-derived absorption coefficients produce a difference of about $0-1 \%$ in the same direction as B\&P.

The known seasonality of the difference (Vanicek, 2006; Scarnato et al., 2009) has in the past been investigated with the use of the temperature dependence of the Dobson absorption coefficients alone, as the Brewer wavelengths were chosen so that stratospheric temperature changes would have less effect on the measurement results (Kerr, 2002). The difference between the single- and double-monochromator Brewer instrument is small and only apparent in the spring months. The better rejection of stray light by the internal optics of the double monochromator is more important for measurements at high TOC values encountered in the Northern Hemisphere spring. The difference in the calculation of $\mu$ was not addressed in this study, but the effect of changing the Brewer calculation results in a small decrease in seasonality.

\section{Conclusions}

A new set of ozone absorption coefficients $A_{i}$ for Dobson and Brewer spectrophotometers, using the five cross-section laboratory data sets, was calculated and compared with the previous calculations. The performance of these coefficients was evaluated using the data of simultaneous Brewer and Dobson
Table 10. Percentage Differences vs. the mean of Dobson (CD and AD pair labeled as D CD and D AD) and Brewer RBCC-E triad (B157, B183 and B185) instruments during the 2012 Izaña Langley Dobson-Brewer campaign for the four cross sections used in this study: the operational for Dobson and Brewer instruments (Op), IGQ4, DBM and IUP.

\begin{tabular}{lrrrrr}
\hline & D CD & D AD & B\#157 & B\#183 & B\#185 \\
\hline Op. & -0.78 & -0.78 & 0.68 & 0.69 & 0.96 \\
IGQ4 & -0.37 & -1.18 & 0.68 & 0.69 & 0.96 \\
DBM & 1.76 & 0.94 & -1.45 & -1.44 & -1.17 \\
IUP & -0.20 & 0.10 & -0.05 & -0.04 & 0.24 \\
\hline
\end{tabular}

observations during the CEOS calibration campaign and the ozone observations at Arosa. The main conclusions of our study are as follows:

1. The Brewer and Dobson instrument results agree best when the absorption coefficients used are based on the IUP XS. The application of the temperature-dependent absorption coefficients substantially reduces the seasonality found in the Arosa Brewer-Dobson record. The DBM set also reduces the seasonality, but the change in absolute scale in the Brewer instrument compared to the Dobson results makes its use unsuitable for the network.

2. The temperature dependence values obtained confirm the hypothesis of Kerr (2002): the systematic annual differences between Brewer and Dobson instruments are due to the different temperature dependence in the instruments' ozone retrieval algorithm. With the Brewer instrument, this is small: less than $0.01 \%{ }^{\circ} \mathrm{K}^{-1}$. The suggestion of Kerr et al. (1988), that this difference is due to the temperature dependence in the Dobson algorithm, is also confirmed.

3. The Dobson record will change by less than $1 \%$ using any one of these XS data sets. A change in the temperature-dependent absorption coefficients provides the most benefit by removing an artificial seasonality in the ozone record. The application of the temperature-dependent absorption coefficients will be station dependent, as knowledge of the stratospheric temperature record over the station is required. The determination of the best method to determine this record is a subject for another study.

4. The calculation of the DXS for a particular Brewer instrument is very sensitive to both the XS and the handling of the XS (editing, smoothing, etc.); these differences can be as large as $1 \%$ in ozone.

5. As suggested by Kerr (2002), a direct measurement of the cross section by the instrument can help to validate different strategies for the calculation of the DXS 
for the network instruments. The method requires an independent source of stratospheric temperature.

6. The existing Brewer record of TOC can be adjusted to the IUP scale through the record of the wavelength calibrations. Using the average Brewer value, the maximum uncertainty based on 123 instruments was $0.4 \%$; using the known operational absorption coefficient, that uncertainty can be reduced to $0.1 \%$.

\section{Appendix A}

Table A1. Glossary.

\begin{tabular}{|c|c|}
\hline ACSO & Absorption Cross Sections of Ozone \\
\hline $\mathrm{B} \& \mathrm{P}$ & $\begin{array}{l}\text { Generally refers to the determination of an ozone } \\
\text { cross-section database determined by Bass, A. M. } \\
\text { and Paur, R. J., published in } 1985 \text {. }\end{array}$ \\
\hline B05 & $\begin{array}{l}\text { The B\&P cross-section database weighted by the } \\
\text { top of the atmosphere solar spectrum and } \\
\text { midlatitude ozone and temperature profiles. This } \\
\text { set was using in the re-evaluation of the Dobson } \\
\text { absorption coefficients in Bernhard et al. (2005). }\end{array}$ \\
\hline BOp & $\begin{array}{l}\text { The official cross-section database used to } \\
\text { determine the absorption coefficients for Brewer } \\
\text { instruments. }\end{array}$ \\
\hline DBM & $\begin{array}{l}\text { Generally refers to an ozone cross-section data } \\
\text { determined by Daumont, D.; Brion, J., and Mal- } \\
\text { icet, J. in the early 1990s. }\end{array}$ \\
\hline DBML & $\begin{array}{l}\text { The DBM ozone cross section expressed as } \\
\text { quadratic polynomial approximation in } \\
\text { temperature at each wavelength registration, } \\
\text { determined by Liu et al. (2007). }\end{array}$ \\
\hline DBMQ & $\begin{array}{l}\text { The DBM ozone cross section expressed as } \\
\text { quadratic polynomial approximation in } \\
\text { temperature at each wavelength registration. }\end{array}$ \\
\hline DXS & Differential cross section \\
\hline FWHM & $\begin{array}{l}\text { Full width at half maximum, a measure of the } \\
\text { spectral band pass of a slit in a spectrometer. }\end{array}$ \\
\hline IGACO & $\begin{array}{l}\text { Integrated Global Atmospheric Chemistry } \\
\text { Observations }\end{array}$ \\
\hline IGQ4 & $\begin{array}{l}\mathrm{B} \& \mathrm{P} \text { cross-section database published on the } \\
\text { IGACO website. }\end{array}$ \\
\hline IUP & $\begin{array}{l}\text { The ozone cross-section database determined by } \\
\text { Institute of Environmental Physics, University of } \\
\text { Bremen, at } 10 \text { temperatures per wavelength } \\
\text { registration. }\end{array}$ \\
\hline IUPQ & $\begin{array}{l}\text { The IUP ozone cross section expressed as } \\
\text { quadratic polynomial approximation in } \\
\text { temperature at each wavelength registration. }\end{array}$ \\
\hline $\mathrm{RBCC} / \mathrm{RDCC}$ & $\begin{array}{l}\text { Regional Brewer Calibration Centre/Regional } \\
\text { Dobson Calibration Centre }\end{array}$ \\
\hline TOC & Total column ozone \\
\hline
\end{tabular}

Acknowledgements. The authors wish to thank all the Dobson and Brewer operators participating in the calibration campaigns. Without their work and dedication this work would be have been not possible. This study and the campaigns were supported to a great extent by the ESA project "CEOS Intercalibration of Ground-based Spectrometers and Lidars" (ESRIN contract 22202/09/I-EC). The authors appreciate the special assistance with this project from G. Bernhard and A. Serdyuchenko, providing information from the 2005 reanalysis of the Dobson absorption coefficients and the IUP data set.

Edited by: M. Van Roozendael 


\section{References}

Bais, A. F., Zerefos, C. S., and McElroy, C. T.: Solar UVB measurements with the double- and single-monochromator Brewer ozone spectrophotometers, Geophys. Res. Lett., 23, 833-836, 1996.

Barnes, J. and Mauersberger, K.: Temperature dependence of the ozone absorption cross section at the 253.7-nm mercury line, J. Geophys. Res., 92, 14861-14864, 1987.

Basher, R. E.: Review of the Dobson spectrophotometer and its accuracy, no. 13 in Global Ozone Research and Monitoring Project, World Meteorological Organization, Genveva, 1982.

Bass, A. M. and Paur, R. J.: The ultraviolet cross-sections of ozone. I. The measurements, II - Results and temperature dependence, in: Atmospheric ozone; Proceedings of the Quadrennial, 1, 606616, 1985.

Bernhard, G., Evans, R. D., Labow, G. J., and Oltmans, S. J.: Bias in Dobson total ozone measurements at high latitudes due to approximations in calculations of ozone absorption coefficients and air mass, J. Geophys. Res, 110, D10305, doi:10.1029/2004JD005559, 2005.

Brion, J., Chakir, A., Daumont, D., Malicet, J., and Parisse, C.: High-resolution laboratory absorption cross section of $\mathrm{O}_{3}$. Temperature effect, Chem. Phys. Lett., 213, 610-612, 1993.

Daumont, Brion, J., Charbonnier, J., and Malicet, J.: Ozone UV spectroscopy I: Absorption cross-sections at room temperature, J. Atmos. Chem., 15, 145-155, 1992.

Dobson, G. M. B.: The evaluation and elimination of errors in the measurement of total ozone when the sun is low, Atmospheric Physics, Clarendon Laboratory, available at: http://www.atm.ox.ac.uk/user/barnett/Dobsonpapers/ DobsonAtmosMemorandum68pt6November1968.pdf, 1968a.

Dobson, G. M. B.: Forty Years: Research on Atmospheric Ozone at Oxford: a History, Appl. Optics, 7, 387-405, 1968 b.

Fragkos, K., Bais, A. F., and Meleti, C.: Effect of Atmospheric Temperature Variations on Total Ozone Measured with a Brewer MKII Spectrophotometer at Thessaloniki, in: Advances in Meteorology, Climatology and Atmospheric Physics, edited by: Helmis, C. G. and Nastos, P. T., Springer Atmospheric Sciences, 959-965, Springer Berlin Heidelberg, 2013a.

Fragkos, K., Bais, A. F., Balis, D., Meleti, C., and Koukouli, M.: The effect of three different absorption cross sections and their temperature dependence on total ozone of a mid- latitude Brewer spectrophotometer, Atmos.-Ocean, doi:10.1080/07055900.2013.847816, 2013b.

Gorshelev, V., Serdyuchenko, A., Weber, M., Chehade, W., and Burrows, J. P.: High spectral resolution ozone absorption crosssections - Part 1: Measurements, data analysis and comparison with previous measurements around $293 \mathrm{~K}$, Atmos. Meas. Tech. Discuss., 6, 6567-6611, doi:10.5194/amtd-6-6567-2013, 2013.

Gröbner, J., Wardle, D. I., McElroy, C. T., and Kerr, J. B.: Investigation of the wavelength accuracy of Brewer spectrophotometers, Appl. Optics, 37, 8352-8360, 1998.

Kerr, J.: New methodology for deriving total ozone and other atmospheric variables from Brewer spectrophotometer direct sun spectra, J. Geophys. Res, 107, 4731, doi:10.1029/2001JD001227, 2002.

Kerr, J., Mcelroy, C., and Olafson, R.: Measurements of ozone with the Brewer ozone spectrophotometer, in: Quadrennial International Ozone Symposium, 74-79, Boulder, Colorado, 1981.
Kerr, J. B., Evans, W. F. J., and Asbridge, I. A.: Recalibration of Dobson Field Spectrophotometers with a Travelling Brewer Spectrophotometer Standard, in: Atmospheric Ozone, edited by: Zerefos, C. S. and Ghazi, A., 381-386, Springer Netherlands, available at: http://link.springer.com/chapter/10. 1007/978-94-009-5313-0_77 (last access: 29 January 2014), 1985.

Kerr, J. B., Asbridge, I. A., and Evans, W. F. J.: Intercomparison of Total Ozone Measured by the Brewer and Dobson Spectrophotometers at Toronto, J. Geophys. Res., 93, 11129-11140, 1988.

Köhler, U.: Recalibration of the hohenpeissenberg dobson spectrophotometer 104 presuming effective absorption coefficients, J. Atmos. Chem., 4, 359-374, 1986.

Köhler, U., Redondas, A., and Kyro, E.: Regional Calibration Centers for Dobson and Brewer in Europe - A joint venture for highest quality in monitoring the ozone layer, in: Quadrennial International Ozone Symposium, Toronto, Canada, available at: http: //larss.science.yorku.ca/QOS2012pdf/5967.pdf (last access: 29 January 2014), ID5967, 2012.

Komhyr, W. D. and Evans, R. D.: Dobson spectrophotometer total ozone measurement errors caused by interfering absorbing species such as $\mathrm{SO}_{2}, \mathrm{NO}_{2}$, and photochemically produced $\mathrm{O}_{3}$ in polluted air, Geophys. Res., 7, 157-160, 1980.

Komhyr, W. D. and Evans, R. D.: Operations handbook ozone observations with a Dobson spectrophotometer, no. 186 in Global Ozone Research and Monitoring Project, World Meteorological Organization,, Geneva, Switzerland, world meteorological organization, Edn. 2006, available at: http://www.wmo.int/pages/ prog/arep/gaw/documents/GAW183-Dobson-WEB.pdf (last access: 29 January 2014), 1980.

Komhyr, W., Grass, R., and Leonard, R.: Dobson spectrophotometer 83 - A standard for total ozone measurements, 1962-1987, J. Geophys. Res., 94, 9847-9861, 1989.

Komhyr, W. D., Mateer, C. L., and Hudson, R. D.: Effective BassPaur 1985 ozone absorption coefficients for use with Dobson ozone spectrophotometers, J. Geophys. Res., 98, 20451-20465, 1993.

Langley, S. P.: Researches on solar heat and its absorption by the earth's atmosphere a report on the Mount Whitney expedition, Government Printing Office, Washington, available at: http://ia700307.us.archive.org/20/items/ researchesonsola00lang/researchesonsola00lang.pdf (last access: 29 January 2014), 1884.

Liu, X., Chance, K., Sioris, C. E., and Kurosu, T. P.: Impact of using different ozone cross sections on ozone profile retrievals from Global Ozone Monitoring Experiment (GOME) ultraviolet measurements, Atmos. Chem. Phys., 7, 3571-3578, doi:10.5194/acp7-3571-2007, 2007.

Malicet, Daumont, D., Charbonnier, J., Parisse, C., Chakir, A., and Brion, J.: Ozone UV spectroscopy. II. Absorption cross-sections and temperature dependence, J. Atmos. Chem, 21, 263-273, 1995.

Mayer, B. and Kylling, A.: Technical note: The libRadtran software package for radiative transfer calculations - description and examples of use, Atmos. Chem. Phys., 5, 1855-1877, doi:10.5194/acp-5-1855-2005, 2005.

Molina, L. T. and Molina, M. J.: Absolute absorption cross sections of ozone in the 185- to 350-nm wavelength range, J. Geophys. Res., 91, 14501-14508, 1986. 
Orphal, J.: A critical review of the absorption cross-sections of $\mathrm{O}_{3}$ and $\mathrm{NO}_{2}$ in the ultraviolet and visible, J. Photochem. Photobio. A, 157, 185-209, 2003.

Redondas, A.: Brewer Calibration: Ozone Absorption issues, in: Absorption Cross Sections of Ozone (ACSO), Geneva, available at: http://igaco-o3.fmi.fi/ACSO/presentations_2009/ ground-based/Redondas.pdf, (last access: 29 January 2014), 2009.

Redondas, A. and Cede, A.: Brewer algorithm sensitivity analysis, in: SAUNA workshop, Puerto de la Cruz, Tenerife, Vol. 286, available at: ftp://bdms:arosa90@ftp.tor.ec.gc.ca/Workshops/ Manchester_2007/presentations/Tuesday_June_5/redondas_2. pdf (last access: 29 January 2014), 2006.

Savastiouk, V.: The effect of change of BP to DBM ozone absorption cross sections on total ozone from Brewer, in: Absorption Cross Sections of Ozone (ACSO), Geneva, available at: http://igaco-o3.fmi.fi/ACSO/presentations_2010/ ground-based/OTM_2010_Savastiouk.pdf (last access: 29 January 2014), 2010.

Scarnato, B., Staehelin, J., Peter, T., Gröbner, J., and Stübi, R.: Temperature and slant path effects in Dobson and Brewer total ozone measurements, J. Geophys. Res., 114, D24303, doi:10.1029/2009JD012349, 2009.

Scarnato, B., Staehelin, J., Stübi, R., and Schill, H.: Long-term total ozone observations at Arosa (Switzerland) with Dobson and Brewer instruments (1988-2007), J. Geophys. Res., 115, D13306, doi:10.1029/2009JD011908, 2010.

Serdyuchenko, A., Gorshelev, V., Weber, M., Chehade, W., and Burrows, J. P.: High spectral resolution ozone absorption crosssections - Part 2: Temperature dependence, Atmos. Meas. Tech. Discuss., 6, 6613-6643, doi:10.5194/amtd-6-6613-2013, 2013.
Thomas, R. W. L. and Holland, A. C.: Ozone estimates derived from Dobson direct sun measurements: effect of atmospheric temperature variations and scattering, Appl. Optics, 16, 613-618, doi:10.1364/AO.16.000613, 1977.

Van Roozendael, M., Peeters, P., Roscoe, H. K., De Backer, H., Jones, A. E., Bartlett, L., Vaughan, G., Goutail, F., Pommereau, J. P., Kyro, E., Wahlstrom, C., Braathen, G., and Simon, P. C.: Validation of Ground-Based Visible Measurements of Total Ozone by Comparison with Dobson and Brewer Spectrophotometers, J. Atmos. Chem., 29, 55-83, 1998.

Vanicek, K.: Differences between ground Dobson, Brewer and satellite TOMS-8, GOME-WFDOAS total ozone observations at Hradec Kralove, Czech, Atmos. Chem. Phys., 6, 5163-5171, doi:10.5194/acp-6-5163-2006, 2006.

Vaníček, K., Metelka, L., Skřivánková, P., and Staněk, M.: Dobson, Brewer, ERA-40 and ERA-Interim original and merged total ozone data sets - evaluation of differences: a case study, Hradec Králové (Czech), 1961-2010, Earth Syst. Sci. Data, 4, 91-100, doi:10.5194/essd-4-91-2012, 2012.

Vanier, J. and Wardle, D. I.: The effects of spectral resolution on total ozone measurements, Q. J. Roy. Meteor. Soc., 95, 395-399, doi:10.1002/qj.49709540411, 1969.

Weber, M., Chehade, W., and Spietz, P.: Impact of ozone crosssection choice on WFDOAS total ozone retrieval applied to GOME, SCIAMACHY, and GOME-2 (1995-present), Technical Note Issue 2 with updates from November 2013, in: Contribution to ACSO.(IGACO Activity: Absorption CrossSections for Ozone), Vol. 2, p. 25, Universitat Bremen, Bremen, available at: http://www.iup.uni-bremen.de/UVSAT_ material/manuscripts/weber_acso_201101.pdf (last access: 30 January 2014), 2013. 